\title{
The pervasive impact of diabetes
}

\section{Sophia Samuel}

A faulty circuit spread through the length of me Wires mismatched, currents misfiring. ${ }^{1}$

Diabetes is the fastest growing chronic disease in Australia, with 1.2 million people known to have type 1 , type 2 or gestational diabetes. ${ }^{2}$ An estimated 500,000 Australians have undiagnosed type 2 diabetes. This mirrors a worldwide trend in the 'rise and rise' of diabetes and associated macro and microvascular sequalae. Similar to other rapidly growing non-communicable diseases, a whole-ofsociety approach is ultimately required to implement evidence-based interventions.

General practice remains vital to the health system's response. Prevention, education and early detection of type 2 diabetes by Australian general practitioners (GP) remains an important part of the national approach. Approximately $80 \%$ of adults visit a GP at least once a year, and many asymptomatic or at-risk adults will have risk factors readily identified by taking their history. ${ }^{3}$

The standards for glycaemic targets in type 2 diabetes and optimal mitigation of risk factors are widely accepted and regularly evaluated. ${ }^{3}$ However, as the disease progresses, comorbidities and complications increase, and life expectancy and patient expectations correspondingly decrease. The ongoing expansion of knowledge helps GPs work with the extended clinical management team and their patients to prioritise apparently competing management goals.

Approximately 27,000 Australians start insulin every year. ${ }^{4}$ Sixty per cent have type 2 diabetes, with people from the lowest socioeconomic groups and Aboriginal and Torres Strait Islander peoples being over-represented. In this month's issue, Chin and Robins, both credentialled diabetic educators, explore processes to assist GPs introducing patients to self-administered insulin. ${ }^{5}$

Glycaemic monitoring and control is associated with improved long-term outcomes in people on insulin. ${ }^{6}$ Traditional finger prick blood glucose tests and multiple insulin injections are time consuming and painful, hence the profusion of new innovations in delivery and monitoring, such as those outlined by Pyrlis et al who discuss insulin pumps and continuous glucose monitoring systems. ${ }^{6}$

Though diabetes is mostly thought of as a series of slowly unfolding presentations, glycaemic emergencies do occur. GPs based in rural locations may be called upon to diagnose and provide initial management for patients who may have hyperosmolar hyperglycaemic state. Willix et al provide a useful and relevant management guide for such patients. ${ }^{7}$

A person with type 1 or type 2 diabetes faces both the burden of the disease and the treatment. When quantified as annual healthcare costs, this ranges from $\$ 3500$ to $\$ 16,000$, depending on the presence of microvascular and macrovascular complications. ${ }^{8}$ Primary care comprises $9 \%$ of direct healthcare costs for people with type 2 diabetes; the largest contributor is inpatient care $(32 \%) .{ }^{8}$ What percentage of this inpatient care could have been delivered more efficiently in the community? ${ }^{9}$ What proportion of disease could have been prevented if resources had been made available in primary care for earlier interventions? Population disparitites in glycated haemoglobin measurements suggest the question of type and distribution of healthcare resources needs to be examined further. ${ }^{8,9}$

The majority of the burden of disease is borne, not by the healthcare system, but by the individual with diabetes and, in time, their carers. This can be quantified as out-of-pocket healthcare costs, transport (to and from numerous treatment locations) and home support needs, days away from work and years of productive life lost. ${ }^{8,10}$

The impact of diabetes is pervasive across all aspects of Australian life. Australian primary healthcare has been transitioning from episodic to continuous care of patients with diabetes, with room for innovation and evaluation of various care structures such as the Medical Home. General practice plays a key role in the prevention, detection and overall management strategy for this increasingly common and complex disease.

\section{Author}

Sophia Samuel FRACGP, FARGP; medical editor at Australian Journal of General Practice and a general practitioner in Melbourne, Vic.

\section{References}

1. Cohen C. Foundations II. In: Johnson HT, editor. Shaping the fractured self: Poetry of chronic illness and pain. Perth: UWA Publishing, 2017.

2. Sainsbury E, Shi Y, Flack J, Colagiuri S. Burden of disease for diabetes in Australia: It's time for more action. Sydney: The University of Sydney, 2018.

3. The Royal Australian College of General Practitioners. General practice management of type 2 diabetes: 2016-18. East Melbourne, Vic: RACGP, 2016.

4. Australian Institute of Health and Welfare. Incidence of insulin-treated diabetes in Australia. AlHW: Canberra, 2018. Available at www.aihw.gov. au/reports/diabetes/incidence-insulin-treateddiabetes-australia-2016/contents/introduction [Accessed 9 April 2019].

5. Chin $\mathrm{G}$, Robins $\mathrm{M}$. Teaching patients with type 2 diabetes to self-administer insulin. Aust J Gen Pract 2019;48(5):251-54.

6. Pyrlis F, Brown F, Ekinci El. Recent advances in management of type 1 diabetes. Aust $J$ Gen Pract 2019;48(5):256-61.

7. Willix C, Griffiths E, Singleton S. Hyperglycaemic presentations in type 2 diabetes. Aust $J$ Gen Pract 2019;48(5):263-67.

8. Baker IDI Heart and Diabetes Institute. Diabetes: the silent pandemic and its impact on Australia. Melbourne: Baker IDI Heart and Diabetes Institute 2012. Available at https://static.diabetesaustralia. com.au/s/fileassets/diabetes-australia/e7282521472b-4313-b18e-be84c3d5d907.pdf [Accessed 9 April 2019].

9. Khanna S, Rolls DA, Boyle J, et al. A risk stratification tool for hospitalisation in Australia using primary care data. Sci Rep 2019 Mar 21;9(1):5011. doi: 10.1038/s41598-019-41383-y.

10. Schofield D, Shrestha RN, Cunich MM et al. The costs of diabetes among Australians aged 45-64 years from 2015 to 2030: Projections of lost productive life years (PLYs), lost personal income, lost taxation revenue, extra welfare payments and lost gross domestic product from Health\&WealthMOD2030. BMJ Open 2017;7:e013158. doi: 10.1136/bmjopen-2016-013158. 